\title{
An innovative cathodic protection system for steel framed heritage structures
}

\author{
R. Brueckner, R. Merola \& P. Lambert \\ Mott MacDonald, Materials \& Corrosion Engineering, UK
}

\begin{abstract}
The corrosion of early 20th century steel-framed buildings is resulting in serious damage to the integrity and appearance of many historically important structures. Since the application of cathodic protection to steel framed buildings in the late 1990s it has been proven to provide a low intrusive and aesthetically acceptable technique for the conservation of heritage structures.

The principles of cathodic protection have not changed since its discovery by Humphry Davy in 1824 but have been adapted to a wide range of structures over the subsequent 190 years. The systems itself have been refined and improved over time except in the case of steel framed buildings where it is still in its early years.

This paper discusses the application of an innovative cathodic protection system on steel framed buildings that utilises a geopolymer with admixed carbon fibres. The system does not require the installation of additional discreet anodes and is in the form of a repointing mortar in the joints of the cladding from where it is able to provide protection. The principles of the system and its first commercial application are presented.

Keywords: steel framed, heritage, cathodic protection, geopolymer.
\end{abstract}

\section{Introduction}

Cathodic protection dates back to 1824 when Humphry Davy [1] developed a system to prevent the corrosion of the copper cladding to ship hulls in seawater. This corrosion protection method has only been adopted and developed for the use on structures and buildings from the late 1950s onwards in the case of reinforced concrete and much more recently in the case of steel framed buildings. The construction of steel framed masonry clad buildings became popular at the turn of 
the $19^{\text {th }}$ century and satisfied the requirements to build higher, faster and in a more cost efficient manner. The then common construction materials of brick, stone masonry and concrete were found to be unsuitable to allow cities to grow vertically but still maintain large openings for doors and windows. This form of construction, using a structural steel frame, was initially employed in Chicago and subsequently used in most major cities in the USA and Europe.

Over the 75 to 100 years following construction, the protection offered by the surrounding mortar and masonry has broken down and the steel has started to corrode, resulting in cracking and displacement of cladding. Nearly a century after the beginning of steel frame construction and almost two centuries after the initial development work by Humphry Davy, CP was identified as a suitable technique to halt corrosion of the deteriorating structural frames.

In 1997, Gloucester Road Underground Station [2] became the first full structure to be protected by such a system (see Figure 1). CP systems for steel framed buildings have developed considerably since 1997 but typically comprise discreet anodes installed into the joints at approximately $500 \mathrm{~mm}$ centres to minimise the impact on the appearance of, often historic, heritage structures.

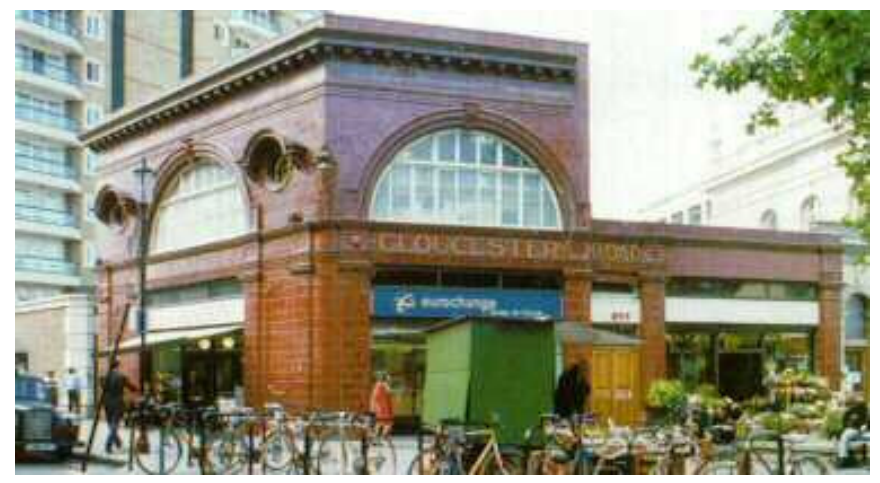

Figure 1: Gloucester Road Underground Station.

\section{Steel frame corrosion}

In the presence of moisture and oxygen, steel and other simple ferrous alloys undergo corrosion resulting in a loss of metal and the formation of expansive corrosion products commonly referred to as rust. The rate and nature of the process depends on alloy composition, environmental factors, design and the presence of additional protection.

In its simplest form the corrosion process can be represented by two dissimilar metals in an aqueous electrolyte, joined to allow electrons to pass from anode to cathode with an associated loss of metal from the anodic areas. In reality, when a metal corrodes, anodic and cathodic areas can be formed on a single surface in contact with the aggressive aqueous environment. This is shown in Figure 2. As a result, corrosion can occur at a large number of sites over the surface of the metal. Dissolved metal ions react with hydroxyl ions to form the corrosion products [3]. 


\section{ELECTROLYTE}

(Water in mortar, soil, or concrete)

Current carried by ions
IN THE ELECTROLYTE

Anions move to the anode (hydroxide, chloride, sulphate)

Cations move to the cathode

(hydrogen, sodium, calcium)

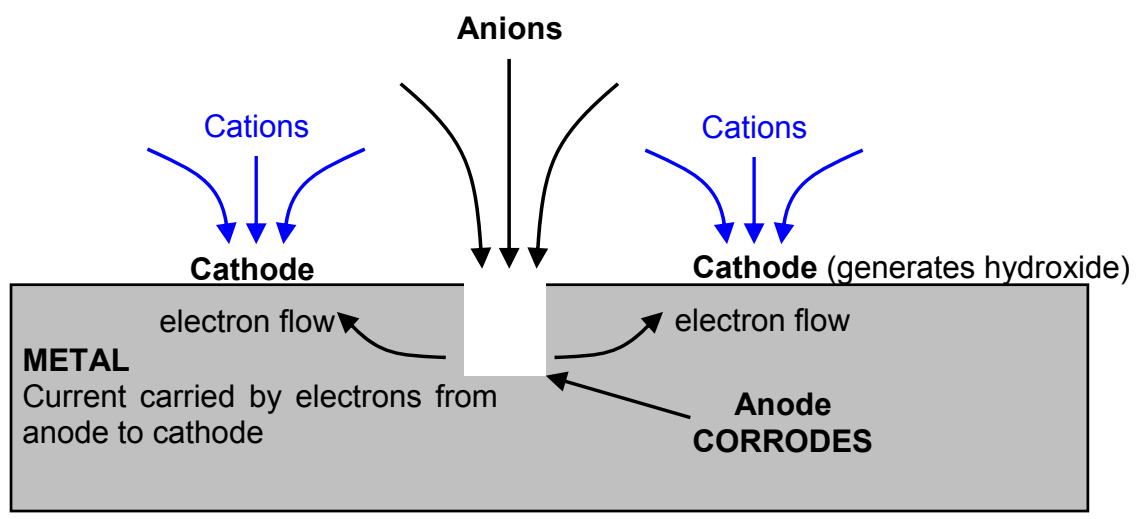

Figure 2: The corrosion process.

The rate of corrosion is largely dependent on the relative humidity and in the case of steel, corrosion commences at a slow rate at approximately $60 \% \mathrm{RH}$. The rate increases at $75-80 \% \mathrm{RH}$ and again at $90 \%$. Contamination of the environment, such as the presence of salts, reduces the relative humidity at which corrosion initiates [4]. Controlling the relative humidity of encased steel can provide an effective means of controlling corrosion. The removal or exclusion of excess moisture also removes or prevents the ingress of potentially aggressive species [5].

In the case of steel framed buildings the protection against excess moisture and ingress of aggressive species was provided by its method of construction. The protection has typically consisted of a cement wash or thin bituminous coating followed by partial encasement in concrete or mortar as shown in Figure 3. Over its lifetime the joints, pointing and flashing gradually deteriorates allowing water to ingress. In conjunction with the carbonation of the cementitious encasement material that had originally provided a protective barrier, corrosion has been able to initiate. The mortar and masonry acted as a dense layer on the surface and, where Portland cement was also used, formed a stable passivation layer at the interface as a result of the high alkalinity.

Once corrosion has commenced, the more voluminous corrosion products cause cracking and displacement of the brick or stone cladding which can further open up joints and cracks, permitting more water to penetrate. Figure 4 shows the degradation of a wrought iron column encased in masonry cladding and Figure 5 the effects of corrosion on the cladding. 


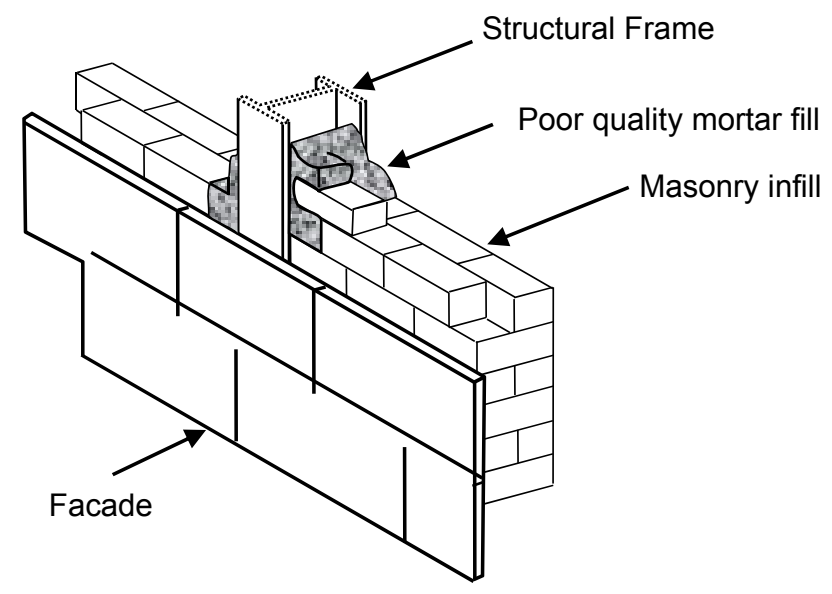

Figure 3: Typical construction detail.

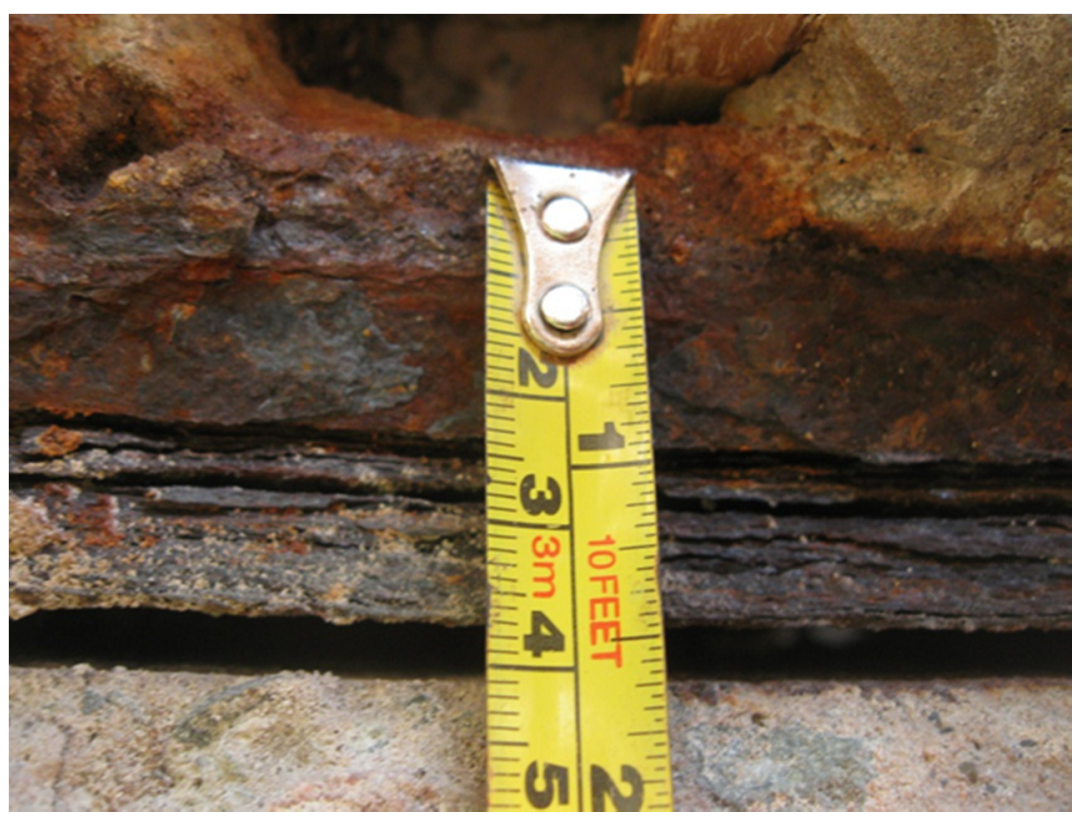

Figure 4: Corrosion of a masonry encased wrought iron beam. 


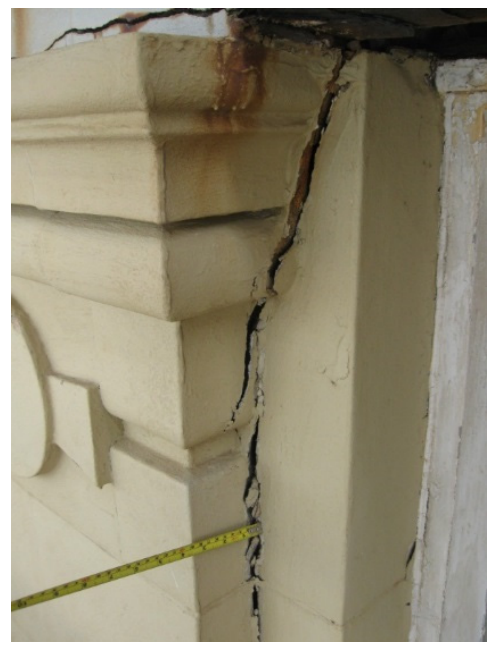

Figure 5: Damage due to steel frame corrosion.

\section{Cathodic protection}

Traditional methods of repair require the displaced masonry to be removed and the corroded frame to be cleaned and recoated prior to reinstating the cladding and pointing. This is not only disruptive and expensive, but generally leaves large areas of corrosion where no displacement of the masonry has occurred untreated. The level of damage to the masonry will commonly require new material to be employed in the reconstruction, thereby undermining the authenticity of the structure.

Since the late 1990s, cathodic protection has provided a technically feasible, reliable and commercially viable technique to address the ongoing deterioration of steel framed buildings and to maintain the appearance of the buildings. Conventional repairs of the deteriorated cladding, pointing and flashing are still required at the time of the installation of $\mathrm{CP}$ system but frequent interventions should not be subsequently required.

Cathodic protection makes use of the principles of corrosion of steel where anodic and cathodic sites are formed on the surface of the steel. Metal is dissolved at the anodes whereas the steel remains unaffected at the cathodes. By applying a small externally generated current to the steel it is possible to make all the steel cathodic and therefore non-corroding. The externally applied current can either be produced by a material that will corrode preferentially to the steel, a galvanic anode such as zinc, or provided by a low voltage DC source via an effectively inert material to provide an impressed current to the steel.

Impressed current systems are driven by the application of a direct current through an inert or effectively inert anode, commonly manufactured from mixed metal oxide (MMO) activated titanium anodes or titanium oxide ceramic (titania). The potential of the reinforcement shifts more negative, suppressing the anodic 
reaction by increasing the applied current. Ideally the potential should be suppressed to a level where corrosion is not thermodynamically possible, but any negative shift in the potential will lead to a reduction in corrosion rate.

By using CP, hydroxyl ions are produced at the steel frame, slowly increasing the alkalinity. This will provide some protection if the $\mathrm{CP}$ system should fail during its life, typically 25 to 50 years. Failure of the CP system will be identified during the regular monitoring that is required to address variations in current requirements of the system. Periodic replacement of failed power supplies and monitoring electrodes may be expected during this period.

\section{CP by using carbon fibre geopolymers}

Conventional CP systems for steel framed buildings typically employ ribbon or rod anodes installed in various grid patterns into the masonry as shown in Figure 6. To simplify the requirements for installation and to improve the durability of $\mathrm{CP}$ systems it became apparent that it would be a significant technical and commercial advantage if the role of the anode could be replaced by the mortar used in the repointing.

The key component to the new system is a highly durable and conductive material - a geopolymer with admixed carbon fibres. A geopolymer is essentially an artificial stone produced by cross-linking inorganic mineral molecules by a process known as polycondensation to produce a highly stable and durable material with excellent thermal and chemical resistance properties. By comparison, conventional Portland cement based materials react by hydration to produce a crystal structure containing bound water, leaving the material far more susceptible to thermal and chemically induced damage. A further advantage of geopolymers is that they can be produced exclusively from industrial by-products, including blast furnace slag, fly ash, metakaolin and waste silicate solutions.

The main disadvantage of the geopolymer is its very low electrical conductivity. This is addressed by the addition of chopped carbon fibres to the mix [6]. The fibres also compensate the shrinkage that is commonly encountered in geopolymers.

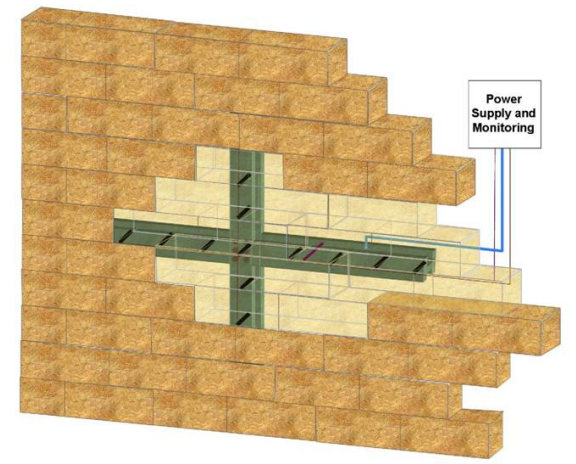

Figure 6: Schematic representation of a conventional CP installation. 


\section{Application of geopolymer CP system}

The new anode system was first assessed in a trial installation at Leeds Civic Hall, a magnificent steel-framed, Portland stone clad Grade II* listed building that was designed by Vincent Harris and opened in 1933 (Figure 7). Areas of the structure were in need of repointing and showing early signs of steel frame corrosion.

A trial installation, comprising both the conductive geopolymer and a conventional rod anode CP system, was installed to part of the rear façade. In addition to the conductive geopolymer used to repoint the raked out joints, a conductive carbon chord was employed as a primary feed to supply and distribute the low voltage DC current. Monitoring of the two systems showed that the geopolymer CP system achieved equally effective protection to the steel frame as the conventional CP system.

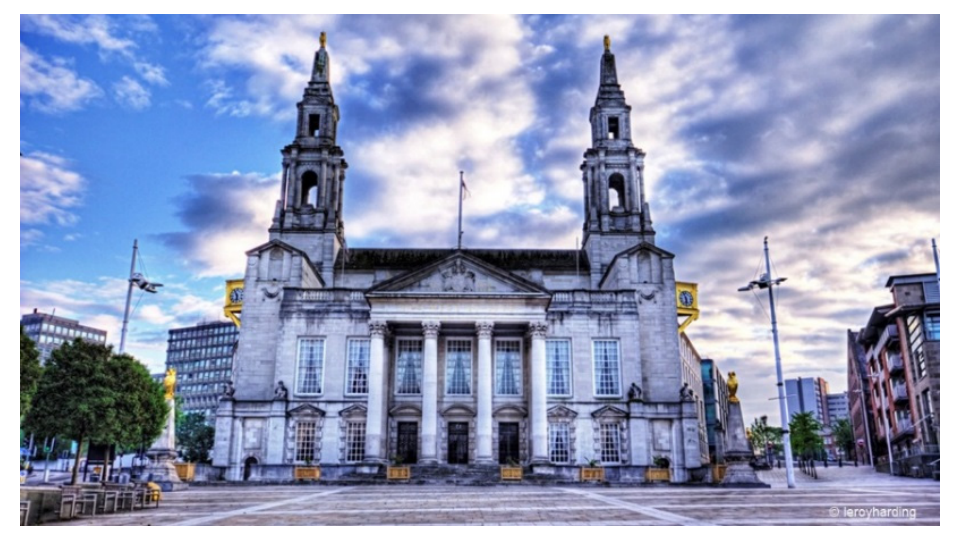

Figure 7: Leeds Civic Hall.

The first commercial system was designed and installed at the main entrance to an historic Kansas City building, Missouri, USA that required a durable and invisible repair technique. The 922 Walnut building was constructed in 1906 by Fullers, who were also responsible for the Flatiron Building in New York. Upon its completion it was the tallest building in Kansas City and its first skyscraper. While the facade remained in good condition through the majority of the $20^{\text {th }}$ century, by the start of the new millennium it was showing signs of corrosion to the steel frame and cracking of the granite used in the construction of its grand main entrance (Figure 8).

Due to the complex structure of the entrance, including integral vaulted ceilings, a 3D model was developed to assist with the design of the system in collaboration with C-Probe Technologies who provided the hardware and site support to the main contractor during installation. The only change from the system employed at Leeds is that the primary feed has been changed from a carbon chord to a mixed metal oxide coated titanium wire which can carry more current and is more durable. The areas of application of the geopolymer are shown in Figure 9 representing the location of the steel frame behind the cladding. 


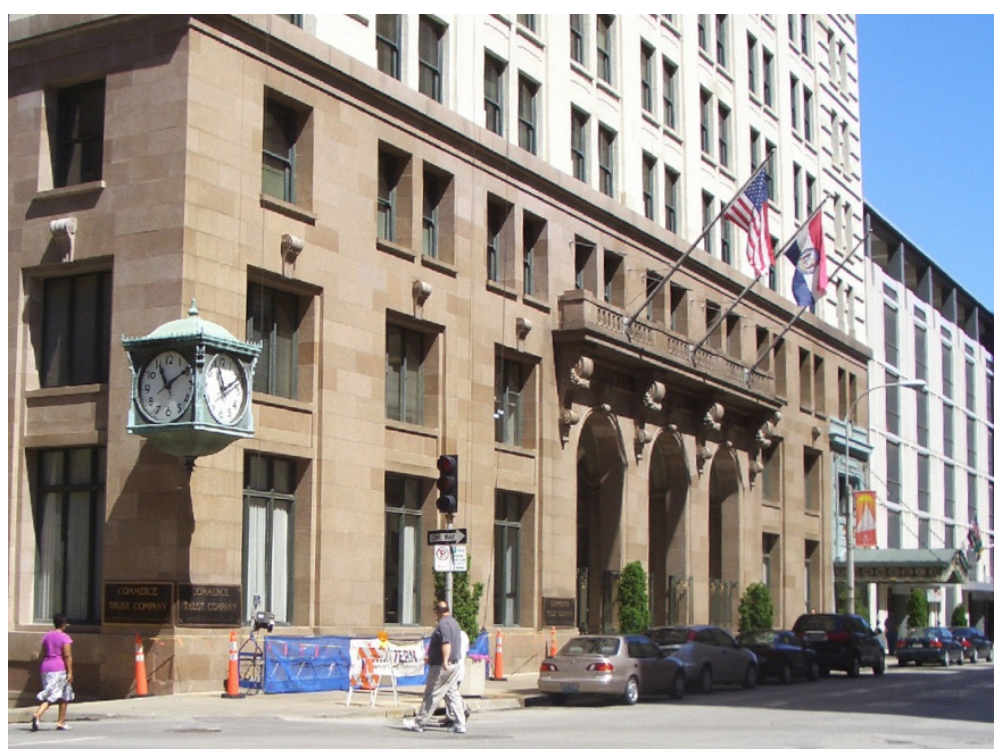

Figure 8: 922 Walnut, Kansas City.
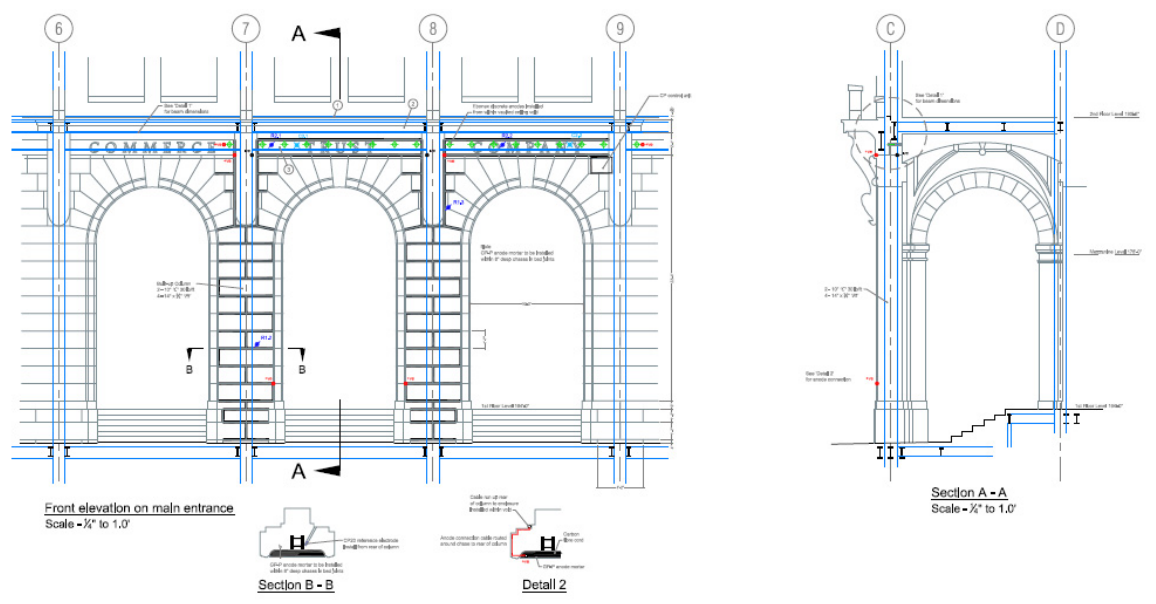

Figure 9: Areas repointed using the geopolymer anode mortar.

\section{Conclusions}

Nearly two centuries after the development of cathodic protection by Humphry Davy, the application method of CP has been further refined and an innovative material developed that can be combined with the best practices of traditional 
steel-framed building repair to provide a sustainable and durable solution for the sympathetic repair of sensitive heritage structures. It can be applied on a wide range of historic structures to achieve very long extensions in service life with minimal levels of intrusion and disruption to the original fabric.

The main advantage of the new system is that the repair is significantly less intrusive than conventional $\mathrm{CP}$ by incorporating the anode into the repointing process of the cladding.

The trial and first commercial installation of the geopolymer CP system have both shown satisfactory protection results to the steel frame and continue to operate effectively. The system has since been employed on further similar structures and is planned for use many others.

\section{References}

[1] Davy H, 'On the corrosion of copper sheeting by seawater, and on methods of preventing this effect, and on their application to ships of war and other ships'. Proceedings of the Royal Society, 114, pp. 115, 151-246, 328-346, $1824,1825$.

[2] Evans B, 'Electric refurbishment', The Architects' Journal, pp. 59-61, November 1997.

[3] Lambert, P, 'Corrosion mechanisms - An introduction to aqueous corrosion', Technical Note No. 5, Corrosion Prevention Association, UK, 4 pp., 2002.

[4] Vernon, WHJ, 'A laboratory study of the atmospheric corrosion of metals' Trans. Faraday Society, 31, 1935.

[5] Lambert, P, 'Controlling moisture', Construction Repair: 6, pp. 29-32, March/April 1997.

[6] Lambert, P, Mangat, P, O’Flaherty, F \& Nguyen, CV, 'A combined solution for the strengthening and corrosion protection of reinforced concrete structures', Concrete, pp. 15-18, February 2015. 